\title{
- www.czasopisma.pan.pl

\section{Structural Zones in Large Static Ingot. Forecasts for Continuously Cast Brass Ingot}

\author{
W. Wołczyński ${ }^{\text {a }}$, Z. Lipnicki ${ }^{\text {b }}$, A.W. Bydałek ${ }^{\text {c }}$, A.A. Ivanova ${ }^{\text {d }}$ \\ ${ }^{a}$ Institute of Metallurgy and Materials Science, Reymonta 25, 30059 Kraków, Poland \\ ${ }^{\mathrm{b}}$ University of Zielona Góra, Szafrana 15, 65516 Zielona Góra, Poland \\ ${ }^{c}$ AGH University of Science and Technology, A. Mickiewicza 30, 30-059 Kraków, Poland \\ ${ }^{\mathrm{d}}$ Institute of Applied Mathematics and Mechanics, Rosa Luxemburg 74, 83-114 Donetsk, Ukraine \\ * Corresponding author. E-mail address: w.wolczynski@imim.pl
}

Received 08.03.2016; accepted in revised form 04.08.2016

\begin{abstract}
Some metallographic studies performed on the basis of the massive forging steel static ingot, on its cross-section, allowed to reveal the following morphological zones: a/ columnar grains (treated as the austenite single crystals), b/ columnar into equiaxed grains transformation, $\mathrm{c}$ equiaxed grains at the ingot axis. These zones are reproduced theoretically by the numerical simulation. The simulation was based on the calculation of both temperature field in the solidifying large steel ingot and thermal gradient field obtained for the same boundary conditions. The detailed analysis of the velocity of the liquidus isotherm movement shows that the zone of columnar grains begins to disappear at the first point of inflection and the equiaxed grains are formed exclusively at the second point of inflection of the analyzed curve. In the case of the continuously cast brass ingots three different morphologies are revealed: a/ columnar structure, b/ columnar and equiaxed structure with the CET, and c/ columnar structure with the single crystal formation at the ingot axis. Some forecasts of the temperature field are proposed for these three revealed morphologies. An analysis / forecast of the behavior of the operating point in the mold is delivered for the continuously cast ingot. A characteristic delay between some points of breakage of the temperature profile recorded at the operating point and analogous phenomena in the solidifying alloy is postulated.
\end{abstract}

Keywords: Theory of crystallizations, Thermal gradients' field, Structural zones, Brass ingot, Operating point in the mold

\section{Introduction}

Usually, the solidification zones' selection is made due to the theoretical model associated with the characteristic behavior of the solid / liquid interface undercooling, [1]. Next, the theory [1] was developed by introducing the convection effect on the segregation, [2]. However, the structural zones in the solidifying ingot are formed as a result of the constrained or unconstrained solidification, [3]-[7]. Consequentially, the temperature field in the ingot can be subjected to the detailed analysis, [8]-[13].

The thermal gradients' field simulation in a static ingot is suggested in the current model as an alternative method for the structural zones' selection, [14]. The thermal gradients' field simulation is usually preceded by the numerical calculation of temperature field, [15]. As a continuous cast method can be divided into two stages: $a$ / initial transient cast and b/ final steady state cast, it is postulated that the initial transient period of continuously cast ingot corresponds well to the static method of ingots' cast solidification. Therefore, some comparisons between both static ingot solidification and initial period of the continuously cast ingot solidification are justified.

The suggested comparison is focused on the behavior of the so-called operating point situated in the middle-width of the mold where the temperature profile can be easily measured. 
It is important, because the temperature profile predicted / measured at the operating point of the mold should be the echo of the CET phenomenon which occurs in the solidifying alloy. This profile presents some characteristic points of breakage. These points are expected to appear in some characteristic time delay and for the identical time periods to the analogous points calculated for a given alloy solidification and especially for the CET - phenomenon.

\section{Visualization of a Static Ingot's Zones}

Experimental observations of steel morphology on the vertical cut at the mid-depth of the massive forging ingot are shown in Fig. 1. An identification of different types of structure allows to distinguish columnar structure, Fig. 1a, structural zone in which columnar into equiaxed grains transformation (co-existence) is visible and equiaxed structure, exclusively, Fig. $1 \mathrm{~b}$.

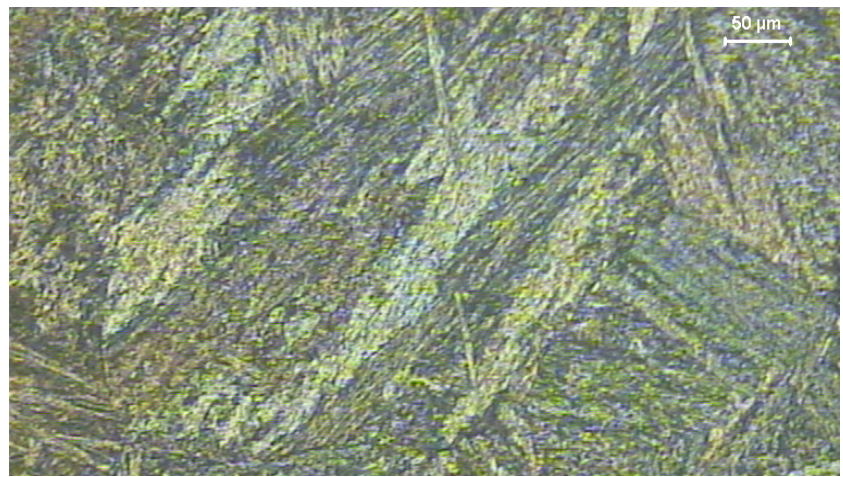

Fig. 1a. Columnar structure revealed within the static steel ingot

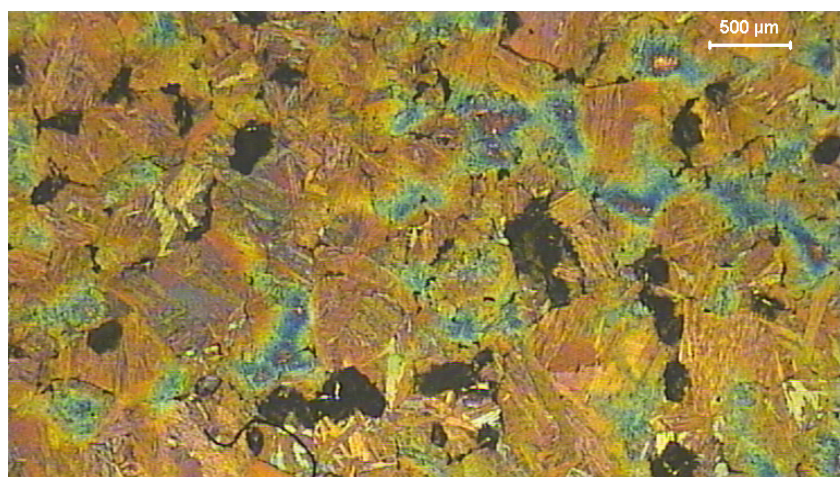

Fig. 1b. Equiaxed structure revealed within the static steel ingot

Some large grains of austenite are well visible in the columnar zone of the static ingot, Fig. 1a. Therefore, these grains can be treated as the austenite single crystals which are the result of the directional solidification, [16]. However, some carbides particles are visible inside every austenite grain. Their location within the austenite grains depends on their diameter and the velocity of the solid / liquid interface movement (the velocity of the columnar austenite grains solidification).

On the other hand the equiaxed grains, revealed in the neighborhood of the massive ingot axis, are globular. Some big carbides are also situated among the equiaxed grains, (black inclusions in Fig. 1b). The phenomenon of the micro-shrinkage is also present in this ingot's zone, (blue / green areas in Fig. 1b).

The structural transformation within the massive ingot cannot proceed sharply. This is time consuming transition (CET) within which a competition between columnar and equiaxed structure formation occurs, [13]. Therefore, at some ingot radius the coexistence of columnar and equiaxed grains is expected, Fig. 2.

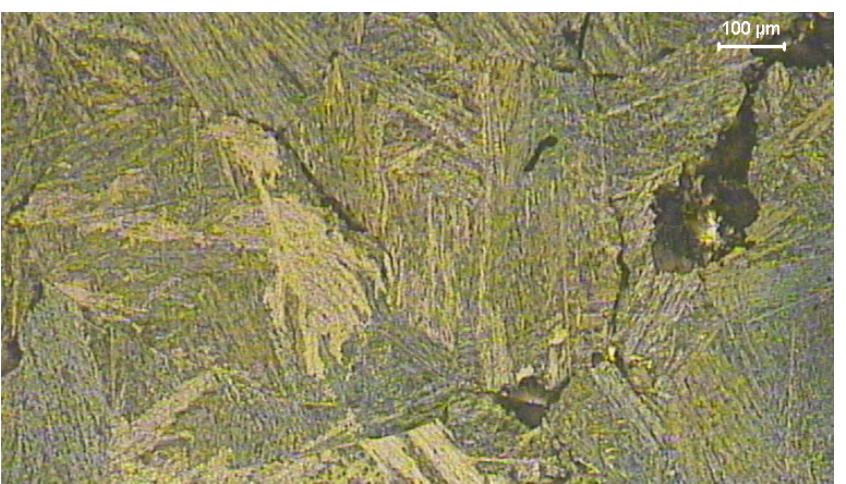

Fig. 2. Columnar and equiaxed grains, together, in the CET zone, that is in the columnar into equiaxed transition zone

\section{Temperature Field's Simulation}

Some simulations performed for the imposed boundary conditions, Fig. 3, for the steel static ingot solidification allow to determine not only the temperature field, Fig. 4, but he position of the liquidus isotherm as well, Fig. 5.

$$
\begin{aligned}
& \mathrm{h}=0.5 \mathrm{~W} / \mathrm{mK} \\
& \theta=50^{\circ} \mathrm{C}
\end{aligned}
$$

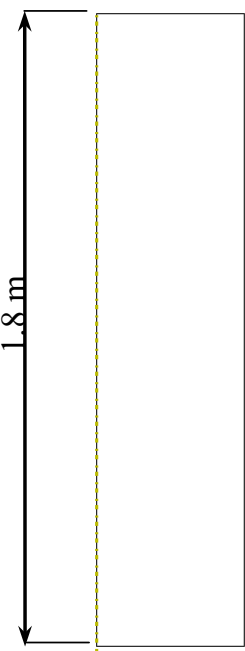

$$
\mathrm{h}=11.45 \mathrm{~W} / \mathrm{mK}
$$$$
\theta=50{ }^{\circ} \mathrm{C}
$$

Fig. 3. Boundary condition applied to the simulation of the temperature field for the solidifying steel ingot; geometry of the ingot / mold is simplified to the roll geometry as visible; outside temperature is assumed to be equal to $50{ }^{\circ} \mathrm{C}$ 

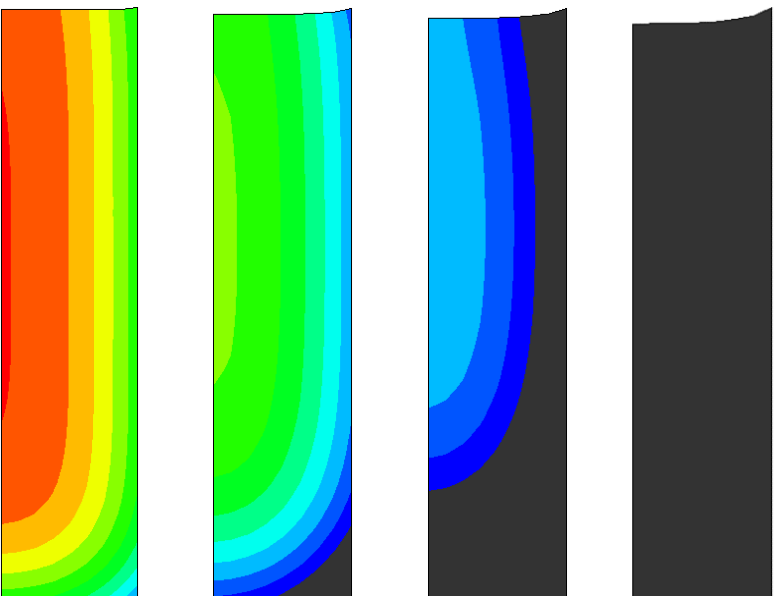

Fig. 4. Temperature field for the solidifying static steel ingot after; $\mathrm{a} / 2[\mathrm{~h}], \mathrm{b} / 5.5[\mathrm{~h}], \mathrm{c} / 9[\mathrm{~h}], \mathrm{d} / 14[\mathrm{~h}]$ of the investigated process

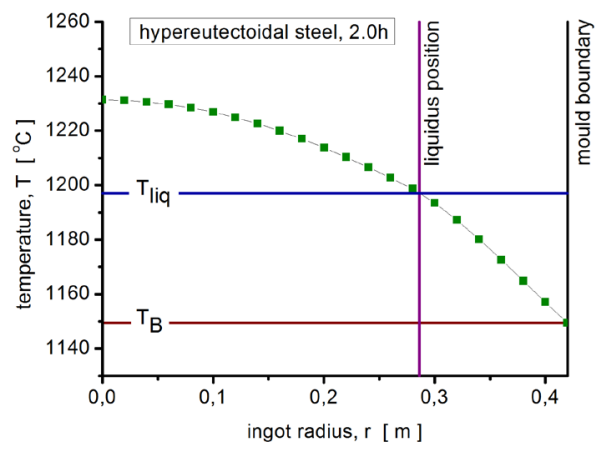

Fig. 5a. Liquidus position on the roll / ingot radius for the 2 [h] of solidification

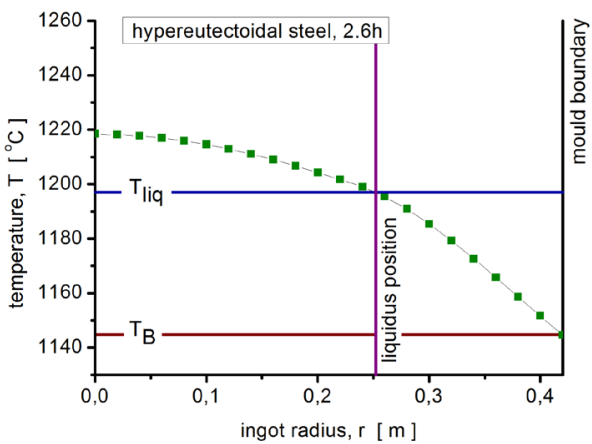

Fig. 5b. Liquidus position on the roll / ingot radius for the 2.6 [h] of solidification

The performed simulation allow to study the velocity of the liquidus isotherm motion together with the velocity of the temperature abandonment at the ingot / mold border, Fig. 6 .

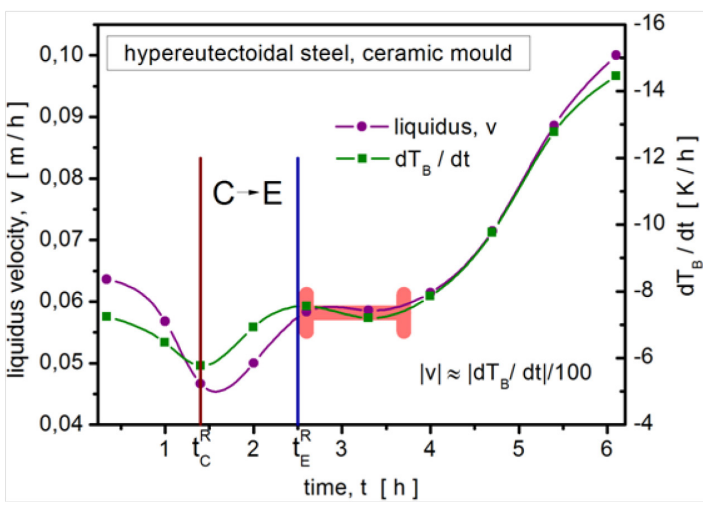

Fig. 6. Velocity of the liquidus isotherm movement; $v$

The $v$ - function evinces some points of inflection. It is postulated from the physical viewpoint that the CET is situated just between first two points of inflection of the $v$ - curve. The first point of inflection appears at about $t_{C}^{R}=1.4[\mathrm{~h}]$ of solidification time, and the second at about $t_{E}^{R}=2.5[\mathrm{~h}]$ of the investigated process.

The temperature field can be numerically transformed into the thermal gradients' field.

An example of this kind of transformation is shown for the solidifying steel ingot, Fig. 7. The knowledge of the liquidus isotherm position on the roll / ingot radius is useful in the determination of the thermal gradient expected at the solid / liquid interface of the growing structure.

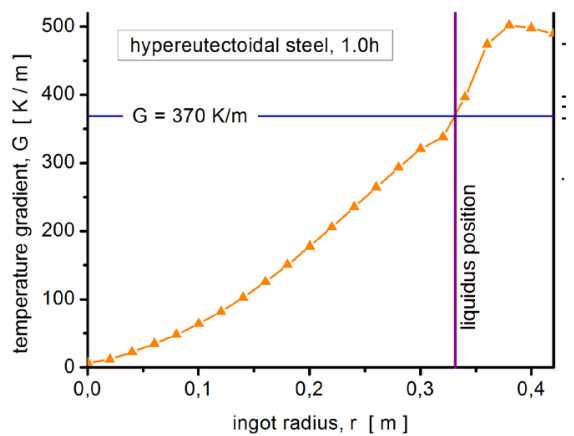

Fig. 7. Thermal gradient determination for the $1[\mathrm{~h}]$ at the liquidus position assumed to be in superposition with the $\mathrm{s} / \mathrm{l}$ interface

According to this mode of interpretation the thermal gradient changes in function of solidification time are drawn for the solidification of the steel static ingot, Fig. 8. 


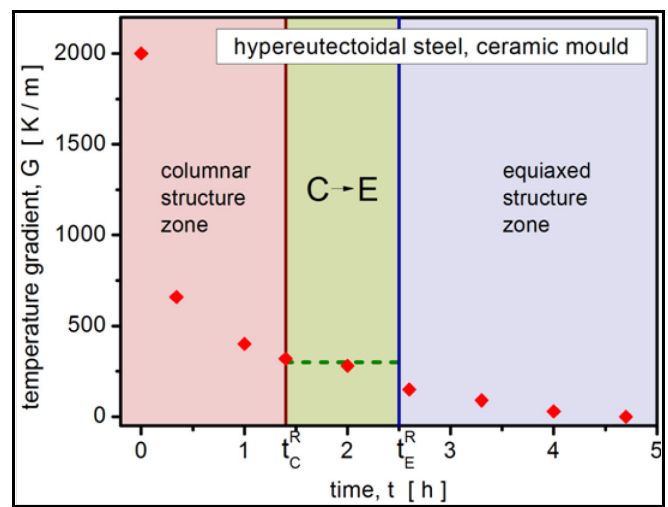

Fig. 8. Thermal gradients' field for the studied solidification time

The $t_{E}^{R}-t_{C}^{R}$ - real period of time within which CET occurs, Fig. 6, is applied to Fig. 8. Thus, the columnar structure, Fig. 1a, appears within the $0 \div t_{C}^{R}$ period of time, Fig. 8 , whereas the $t_{E}^{R} \div 5$, is adequate for the equiaxed structure formation, Fig. $1 \mathrm{~b}$.

\section{Forecasts for Continuously Cast Brass}

A continuous cast method can be divided into two stages: a/ initial transient cast and $\mathrm{b} /$ final steady state cast. It is postulated that the initial transient period of continuously cast ingot corresponds well to the static method of ingots' cast.

The morphology of the ingot obtained within both periods is the same. It consists of columnar and equiaxed grains with the CET between them. However, the ratios of columnar structure zone / equiaxed structure zone seems to be different for these periods. Therefore, the CET localizations are also different for both considered periods in the continuously cast brass ingots.

Thus, it is concluded that the phenomena which occur in the static cast ingot are comparable to those appearing during the initial transient period of continuously cast ingots.

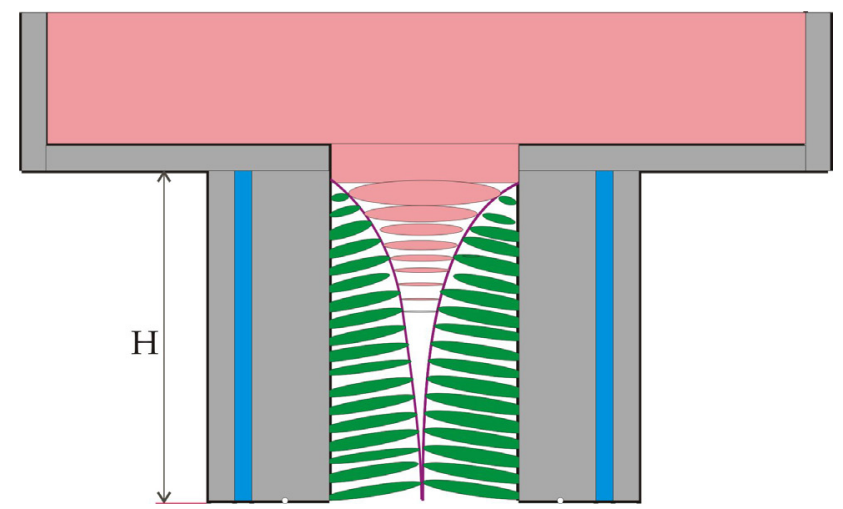

Fig. 9a. Formation of the columnar grains during the continuously cast brass ingots; the white point at the scheme bottom is the operating point to study / measure thermal behavior of the mold, especially, during the initial transient solidification, Fig. 10a.

The structural zones in the continuously cast ingot can be distinguished as follows: a/ columnar structure (grains) on the whole brass ingot diameter, exclusively, from the ingot surface up to the ingot axis, Fig. 9a, $\mathrm{b} /$ columnar structure in the neighborhood of the ingot surface followed by the CET and equiaxed grains zone, Fig. 9b, c/ columnar grains zone accompanied by the appearance of the single crystal localized just at the ingot axis, Fig. 9c.

The thermal gradient is large / steep but changeable during columnar grains growth and constant for a single crystal growth.

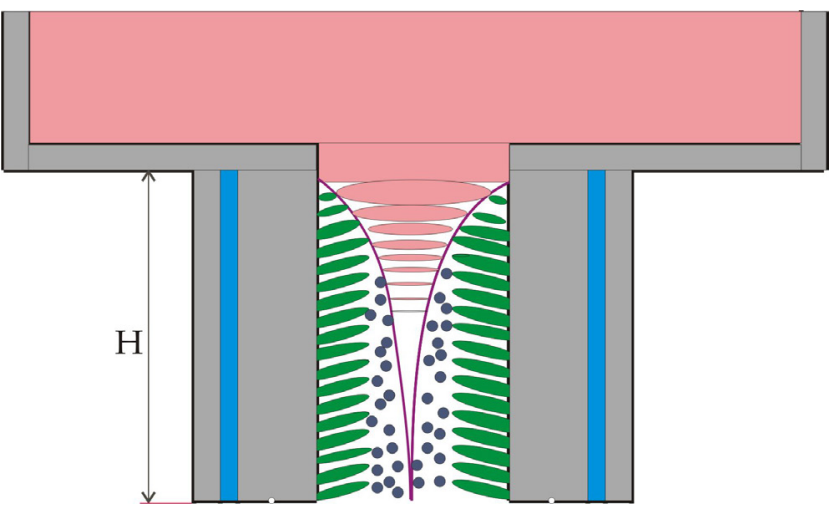

Fig. 9b. Formation of the columnar and equiaxed grains with the CET during the continuously cast brass ingots; the white point at the scheme bottom is the operating point to study / measure thermal behavior of the mold, Fig. 10b.

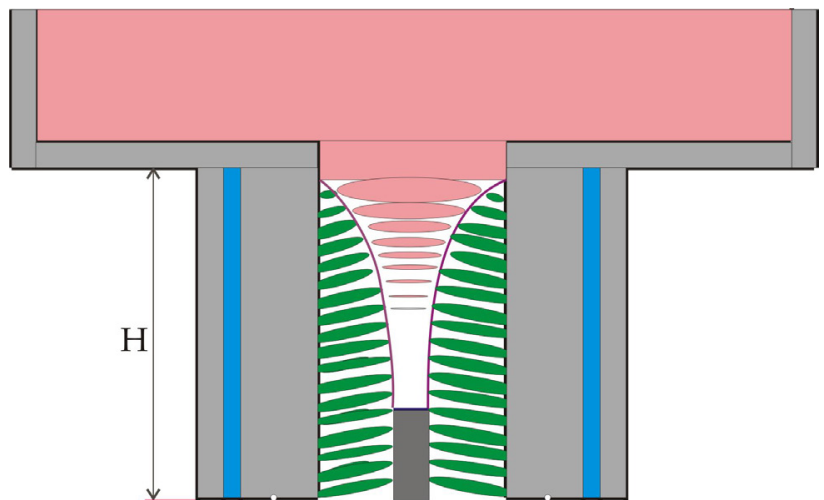

Fig. 9c. Formation of the columnar grains followed by a single crystal growth during the continuously cast brass ingots; the white point at the scheme bottom is the operating point to study / measure thermal behavior of the mold, Fig. 10c.

All the above situations (a/, b/, and c/) are the consequence of the heat transfer within the system and resultant value / direction of a thermal gradient located at the $\mathrm{s} / \mathrm{l}$ interface during solidification.

In the case of the exclusive formation of the columnar structure, Fig. 9a, an increase of temperature should be observed during initial transient period of solidification, Fig. 10a.

$T_{S}$ - isotherm solidus; $T_{M}, T_{C E T}, T_{S C}$ - maximum temperature as observed at the operating point; $r_{o p}$ - radius of the operating point situation; $t_{C E T} ; t_{S C}$ - time of the CET or single crystal growth (SCG) appearance; $\delta t$ - delay between the CET or SCG, and their echo, as recorded at the operating point (defined in Fig. 9). 


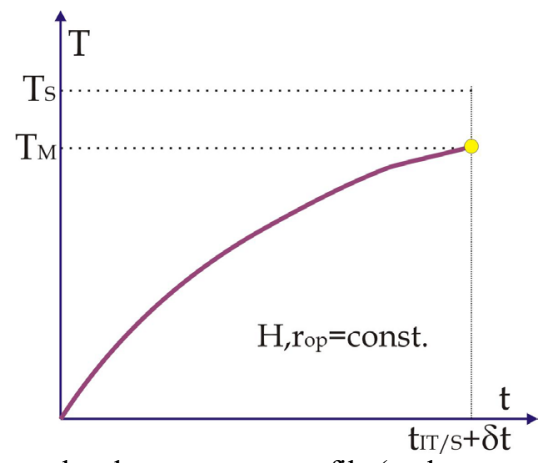

Fig. 10a. Speculated temperature profile (at the operating point in a mold) for columnar structure growth in an ingot

In the case of columnar and equiaxed structure formation with the CET, Fig. 9b, maximum temperature appearance is expected, Fig. 10b.

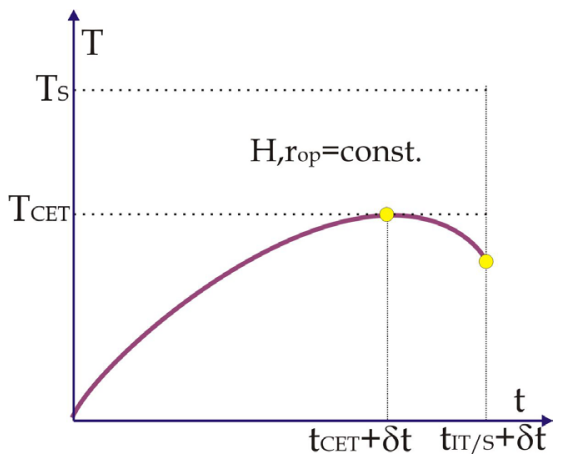

Fig. 10b. Speculated temperature profile (at the operating point in a mold) for columnar / equiaxed growth with the creation of the CET

In the case of columnar structure formation followed by a single crystal growth, Fig. 9c, temperature plateau should be created, Fig. 10c. $T_{C E T}$ - temperature for the CET occurrence at the $t_{C E T}$ - time of solidification; $H$ - crystallizer height.

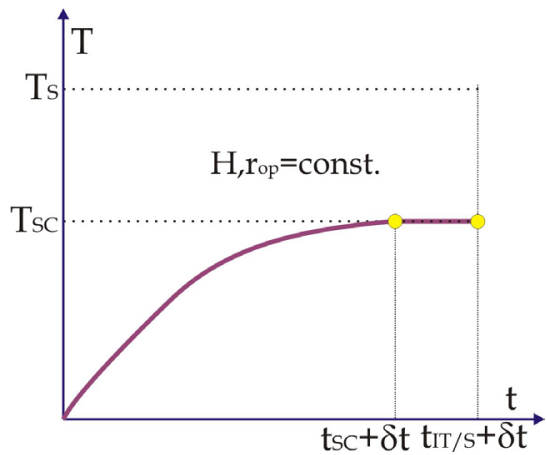

Fig. 10c. Speculated temperature profile for columnar structure formation completed by the single crystal growth

All the temperature profiles predicted for the initial transient period of the continuously cast ingots shown in Fig. 10, can easily be recorded with the use of a thermocouple localized at the operating point of the mold.

\section{Concluding Remarks}

Structural zones created due to solidification of steel massive static ingot have been predicted theoretically, Fig. 6 and confirmed, by the subsequent calculations, Fig. 8. These zones existence was also recorded in the ingot morphology, Fig. 1, Fig. 2. Particularly, the CET transformation is connected with the constant value of the thermal gradients, Fig. 8. It means that in the static massive ingot the CET is not a sharp transformation. It occurs during a certain period of time denoted as, $t_{E}^{R}-t_{C}^{R}$.

The performed numerical simulation for the static steel ingot solidification allows to show that the temperature profile calculated for the operating point in the mold can be presented schematically as in Fig. 11.

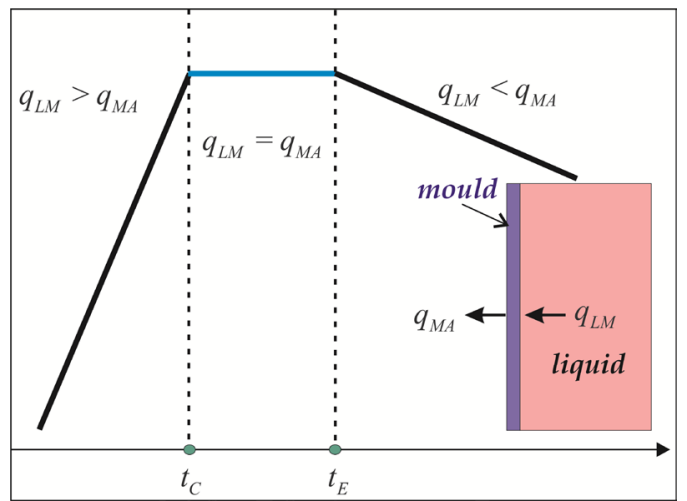

Fig. 11. Temperature profile for the operating point in the mold; $q_{L M}$ - heat flux from the liquid to the mold; $q_{M A}$ - heat flux from the mold to the air.

The described delay between CET appearance and its echo calculated for the operating point in the mold is as follows:

$\delta t=t_{C}^{R}-t_{C} \approx-1.4[\mathrm{~h}]$;

$$
\delta t=t_{E}^{R}-t_{E} \approx-1.4[\mathrm{~h}]
$$

It is obvious that the delay depends on the mold thickness, [17] and to some extent on some structural defects which always are formed in the ingots, [18], [19].

The analysis of the continuously cast brass ingots shows that the CET is a kind of the sharp structural transition, Fig. 10b, in comparison with the time consuming transition observed in static ingot, Fig. 6, Fig. 8, (and its echo shown schematically in Fig. 11).

Generally, three different types of morphology can be distinguished within the continuously cast ingot, especially within the brass ingot. When the columnar structure is formed exclusively in the brass ingot, Fig. 10a, then thermal gradients at the s/1 interface are rather large and directed along the columnar grains. When the equiaxed grains follow then columnar grains appearance the thermal gradients do not change their direction (in the macroscale) but become moderate within the time period employed for the equiaxed grains formation, Fig. $10 \mathrm{~b}$.

In the case, when the SCG is observed along the ingot axis of symmetry, the thermal gradients change their direction and become vertical (parallel to the ingot axis), Fig. 4c. This is an extraordinary example of the brass ingot solidification, Fig. 12. 


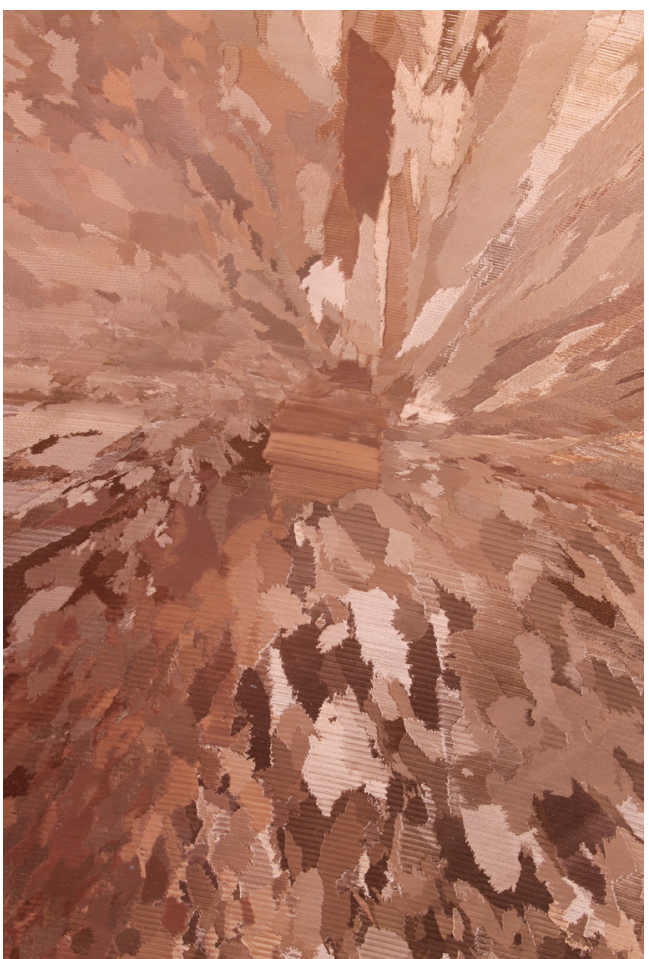

Fig. 12. Upper view of two types of the structural transitions: $\mathrm{C}>\mathrm{SC}$ (columnar into single crystal transition and partially: $\mathrm{E}>\mathrm{SC}$ (equiaxed into single crystal transition)

The $\mathrm{C}>\mathrm{SC}$ transition in the continuously cast brass ingots is well defined by its echo shown schematically in Fig. 10c.

\section{Acknowledgements}

The support was provided by the National Center for Research and Development under Grant No. PBS3 / A5 / 52 / 2015.

\section{References}

[1] Hunt, J.D. (1984). Steady State Columnar and Equiaxed Growth of Dendrites and Eutectics. Materials Science and Engineering. 65, 75-83.

[2] Gu, J.P. \& Beckermann, C. (1999). Simulation of Convection and Macro-Segregation in a Large Steel Ingot. Metallurgical and Materials Transactions. 30A, 1357-1366.

[3] Gandin, Ch.A. (2000). From Constrained to Unconstrained Growth during Directional Solidification. Acta Materialia. 48, 2483-2501.

[4] Gandin, Ch.A. (2000). Experimental Study of the Transition from Constrained to Unconstrained Growth during Directional Solidification. The Iron and Steel Institute of Japan-International. 40, 971-979.

[5] Wołczyński, W. (2010). Constrained / Unconstrained Solidification within the Massive Cast Steel / Iron Ingots. Archives of Foundry Engineering. 10(2), 195-202.
[6] Bogdan, O. (2010). Numerical Analysis of Casting Technology and A-Segregation Prediction in AISI 4340 Forgings Products. Industrial Soft. 1, 1-12.

[7] Wołczyński, W., Kania, B., Wajda, W. Kostrzewa, M. (2011). Space - Time - Structure Map for as Cast Massive Rolls. In Fundamentals of Heat and Mass Transfer - Computational Heat and Mass Transfer, Proceedings of the ASME/JSME 8th Thermal Engineering Joint Conference - AJTEC, March 13-17, 2011. Conference CD: AJTEC-44021, 3.1. Honolulu, Hawaii, USA,; Hishida, K., Klausner, J., Satoh, I., Eds.; ASME/JSME.

[8] Szajnar, J. (2004). The Columnar Crystals Shape and Castings Structure Cast in Magnetic Field. Journal of Materials Processing Technology. 157/158, 761-764.

[9] Gandin, Ch.A., Mosbah, S., Volkmann, Th. \& Herlach, D.M. (2008). Experimental and Numerical Modeling of Equiaxed Solidification in Metallic Alloys. Acta Materialia. 56, 30233035.

[10] McFadden, S., Browne, D.J. \& Gandin, Ch.A. (2009). A Comparison of CET Prediction Methods using Simulation of the Growing Columnar Front. Metallurgical Transactions. 40A, 662-672.

[11] Konozsy, L., Ishmurzin, A., Grasser, M., Wu, M.H., Ludwig, A., Tanzer, R. \& Schutzenhofer, W. (2010). Columnar to Equiaxed Transition during Ingot Casting using Ternary Alloy Composition. Materials Science Forum. 649, 349-354.

[12] Vusanović, I. \& Voller, V.R. (2014). Understanding Channel Segregates in Numerical Models of Alloy Solidification: A Case of Converge First and Ask Questions Later. Materials Science Forum. 790/791, 73-78.

[13] Zimmermann, G., Sturz, L., Billia, B., Mangelinck-Noel, N., Liu, D.R. Nguyen Thi, H., Bergeon, N., Gandin, Ch.A., Browne, D.J., Beckermann, C., Tourret, D. \& Karma, A. (2014). Columnar-to-Equiaxed Transition in Solidification Processing of AlSi7 Alloy in Microgravity -The CETSOL Project. Materials Science Forum. 790/791, 12-21.

[14] Wołczyński, W. (2016) Large Steel Ingots: Microstructure Mathematical Modeling, Entry in: The Encyclopedia of Iron, Steel, and Their Alloys, Ed. CRC Press, Taylor \& Francis Group, Boca Raton, London, New York, Eds Rafael Colas, George E. Totten, v. III, Heat Treatment: Special - Molten, p. 1910-1924.

[15] Wołczyński, W., Guzik, E., Kania, B. \& Wajda, W. (2010). Structure Fields in the Solidifying Cast Iron Roll. Archives of Foundry Engineering. 10(1), 41-46.

[16] Trepczyńska-Łent, M. (2013). Possibilities of the Materials Properties Improvement for the Cementite Eutectic by means of Unidirectional Solidification, Archives of Metallurgy and Materials. 58, 987-991.

[17] Majchrzak, E., Jasiński, M., \& Kałuża, G. (2003). Sensitivity Analysis of Solidification with Respect to the Mold Thickness. Archives of Foundry. 3(9), 305-310.

[18] Ignaszak, Z., \& Ciesiółka, J. (2004). Chosen identification problems of discontinuity in cast iron castings. Archives of Foundry. 4(14), 176-178. (in Polish).

[19] Ignaszak, Z., Popielarski, P., Hajkowski, J., \& Codina, E. (2015). Methodology of Comparative Validation of Selected Foundry Simulation Process. Archives of Foundry Engineering. 15(4), 37-44. 